Supporting information for

\title{
Carbon Nitride Supramolecular Hybrid Material Enabled High-Efficiency Photocatalytic Water Treatments
}

Jinghai Liu* ${ }^{\dagger}$, Shuyuan Xie ${ }^{\dagger}$, Zhibin Geng ${ }^{\ddagger}$, Keke Huang ${ }^{\ddagger}$, Long Fan ${ }^{\dagger}$, Weilei Zhou $^{\dagger}$, Lixin Qiu ${ }^{\dagger}$, Denglei Gao ${ }^{\dagger}$, Lei Ji ${ }^{\dagger}$, Limei Duan* ${ }^{\dagger}$, Luhua Lull, Wanfei Li ${ }^{\S}$, Suozhu Bai ${ }^{\dagger}$, Zongrui Liu ${ }^{\dagger}$, Wei Chen ${ }^{\S}$, Shouhua Feng $* \$$ and Yuegang Zhang* ${ }^{\S}+$

$\dagger$ Inner Mongolia Key Lab of Chemistry of Natural Products and Synthesis of Functional Molecules, College of Chemistry and Chemical Engineering, Inner Mongolia University for the Nationalities (IMUN), Tongliao 028000, People's Republic of China

$\$$ State Key Laboratory of Inorganic Synthesis and Preparative Chemistry, College of Chemistry, Jilin University, Changchun 130012,People's Republic of China

$\S \quad i$-Lab, Suzhou Institute of Nano-Tech and Nano-Bionics, Chinese Academy of Sciences, Suzhou, 215123, People's Republic of China

॥ Faculty of Material Science and Chemistry, China University of Geosciences, Wuhan, 388 Lumo Road, Wuhan 430074, People's Republic of China

${ }^{+}$Department of Physics, Tsinghua University, Beijing 100084, People's Republic of China

*E-mail: ygzhang2012@sinano.ac.cn (Y. G. Z.) or jhliu2015@imun.edu.cn (J. H. L.) or shfeng@mail.jlu.edu.cn (S. H. F.) or duanlmxie@126.com (L. M. D.) 


\section{Figure and Table list:}

Figure S1 UV-Vis spectra of Fe (III) $\left\{\mathrm{PO}_{4}\left[\mathrm{WO}\left(\mathrm{O}_{2}\right)_{2}\right]_{4}\right\}\left(\mathrm{FePW}_{4}\right)$ cluster for the hydrolysis-resistance capability at extended $\mathrm{pH}$ in water.

Figure S2 TEM and STEM images of FePW-g- $\mathrm{C}_{3} \mathrm{~N}_{4}$.

Figure S3 High resolution STEM and EDS elemental analysis of FePW-g- $\mathrm{C}_{3} \mathrm{~N}_{4}$ for observation of cluster localization.

Figure S4 EDS elemental analysis in the area marked by yellow color square.

Figure S5 Specific surface area (SSA) and BJH pore size distributions for FePW-g- $\mathrm{C}_{3} \mathrm{~N}_{4}$ and $\mathrm{g}-\mathrm{C}_{3} \mathrm{~N}_{4}$ control.

Figure S6 Electron Paramagnetic Resonance (EPR) spectra for FePW-g- $\mathrm{C}_{3} \mathrm{~N}_{4}$ and g- $\mathrm{C}_{3} \mathrm{~N}_{4}$.

Figure S7 Supramolecular interactions and structural stability between $\mathrm{Fe}$ (III) $\left\{\mathrm{PO}_{4}\left[\mathrm{WO}\left(\mathrm{O}_{2}\right)_{2}\right]_{4}\right\}$ cluster and $\mathrm{g}-\mathrm{C}_{3} \mathrm{~N}_{4}$ in FePW-g-C $3 \mathrm{~N}_{4}$ probed by FTIR (a) and XRD (b).

Figure S8 High resolution $\mathrm{P}_{2 \mathrm{p}}$ XPS spectra for FePW-g- $\mathrm{C}_{3} \mathrm{~N}_{4}$.

Figure S9 Optical properties of FePW-g- $\mathrm{C}_{3} \mathrm{~N}_{4}$.

Figure S10 Adsorption guided photocatalytic selectivity of FePW-g- $\mathrm{C}_{3} \mathrm{~N}_{4}$ for methylene blue (MB), Rhodamine B (RhB) and Methyl Orange (MO) in water without $\mathrm{H}_{2} \mathrm{O}_{2}$ mediation under simulated solar light irradiation.

Figure S11 UV-Vis spectra for RhB and MO during adsorption and photocatalytic process.

Figure S12 Influences of $\mathrm{pH}$ on adsorption capacity and photocatalytic activity of FePW-g- $\mathrm{C}_{3} \mathrm{~N}_{4}$ for Rhodamine $\mathrm{B}(\mathrm{RhB})$.

Figure S13 Photos for photocatalytic process of FePW-g- $\mathrm{C}_{3} \mathrm{~N}_{4}$ with $\mathrm{H}_{2} \mathrm{O}_{2}$ for degrading $\mathrm{RhB}\left(100 \mathrm{~mL}, 10 \mathrm{mg} \mathrm{L}^{-1}\right)$ under the natural sunlight in winter at $\mathbf{2 8 0} \mathbf{~ K}$, taken at different irradiation time.

Figure S14 Scale-up application of FePW-g- $\mathrm{C}_{3} \mathrm{~N}_{4}$ for photocatalytic degradation of $\mathrm{RhB}\left(10 \mathrm{mg} \mathrm{L}^{-1}\right)$ at $1 \mathrm{~L}$ under the natural sunlight irradiation.

Figure S15 Time-dependent fluorescence signal intensity at $426 \mathrm{~nm}$ of 2-hydroxyterephthalic acid generated by reacting teraphthalic acid with $\bullet \mathrm{OH}$ radicals 
in the aqueous suspension of FePW-g- $\mathrm{C}_{3} \mathrm{~N}_{4}$ mediated with $\mathrm{H}_{2} \mathrm{O}_{2}$ under the irradiation of Xe lamp.

Figure S16 Specific surface area (SSA) of $g-\mathrm{C}_{3} \mathrm{~N}_{4}$. (a) $\mathrm{g}-\mathrm{C}_{3} \mathrm{~N}_{4}-\mathrm{M}$ with SSA of 24.242 $\mathrm{m}^{2} \mathrm{~g}^{-1}$ and (b) $\mathrm{g}-\mathrm{C}_{3} \mathrm{~N}_{4}-\mathrm{L}$ with SSA of $5.940 \mathrm{~m}^{2} \mathrm{~g}^{-1}$.

Figure S17 Adsorption and photocatalytic degradation of RhB (a) and MO (b) by $\mathrm{FeCl}_{3} / \mathrm{g}-\mathrm{C}_{3} \mathrm{~N}_{4}$ mediated by $\mathrm{H}_{2} \mathrm{O}_{2}$ under simulated solar light irradiation for mechanism investigation of the origin of high photocatalytic activity of FePW-g- $\mathrm{C}_{3} \mathrm{~N}_{4}$.

Figure S18 Adsorption and photocatalytic degradation of RhB (a) and MO (b) by $\mathrm{MgPW} / \mathrm{g}-\mathrm{C}_{3} \mathrm{~N}_{4}$ mediated by $\mathrm{H}_{2} \mathrm{O}_{2}$ under simulated solar light irradiation for mechanism investigation of the origin of high photocatalytic activity of FePW-g- $\mathrm{C}_{3} \mathrm{~N}_{4}$.

Figure S19 Effects of specific surface area (SSA) on photocatalytic activity of $g-\mathrm{C}_{3} \mathrm{~N}_{4}$ mediated by $\mathrm{H}_{2} \mathrm{O}_{2}$ under simulated solar light irradiation. $\mathrm{g}-\mathrm{C}_{3} \mathrm{~N}_{4}-\mathrm{L}$ with SSA of 5.94 $\mathrm{m}^{2} \mathrm{~g}^{-1}, \mathrm{~g}-\mathrm{C}_{3} \mathrm{~N}_{4}-\mathrm{M}$ with SSA of $20.24 \mathrm{~m}^{2} \mathrm{~g}^{-1}$ and $\mathrm{g}-\mathrm{C}_{3} \mathrm{~N}_{4}-\mathrm{H}$ with SSA of $73.42 \mathrm{~m}^{2} \mathrm{~g}^{-1}$. Figure S20 Effects of surface defects on photocatalytic activity of $\mathrm{g}-\mathrm{C}_{3} \mathrm{~N}_{4}$ for degradation of $\mathrm{RhB}$ (a) and $\mathrm{MO}(\mathrm{b})$, mediated by $\mathrm{H}_{2} \mathrm{O}_{2}$ under simulated solar light irradiation.

Figure S21 Cycling stability of FePW-g-C $\mathrm{N}_{4}$ for RhB (100 mL, $\left.10 \mathrm{mg} \mathrm{L}^{-1}\right)$ (a) under simulated solar light irradiation and for MO $\left(100 \mathrm{~mL}, 10 \mathrm{mg} \mathrm{L}^{-1}\right)(\mathrm{b})$ under the natural sunlight irradiation .

Table S1 XRF measurement for determination of Fe, P and W in FePW-g- $\mathrm{C}_{3} \mathrm{~N}_{4}$.

Table S2 ICP-AES for measuring the contents of Fe and P in FePW-g- $\mathrm{C}_{3} \mathrm{~N}_{4}$.

Table $\mathbf{S 3}$ Elemental analysis (EA) measurement for $\mathrm{g}-\mathrm{C}_{3} \mathrm{~N}_{4}$.

Table S4 Bulk and surface Compositions of $\mathrm{g}-\mathrm{C}_{3} \mathrm{~N}_{4}$ determined by EA and XPS.

Table S5 Surface compositions determined by XPS for g- $\mathrm{C}_{3} \mathrm{~N}_{4}-\mathrm{L}$ and $\mathrm{g}_{-} \mathrm{C}_{3} \mathrm{~N}_{4}-\mathrm{M}$. 


\section{Experimental}

Preparation of $g-C_{3} N_{4}$ : Graphitic carbon nitride $\left(\mathrm{g}-\mathrm{C}_{3} \mathrm{~N}_{4}\right)$ was prepared according to our previously reported method ${ }^{[\mathrm{s} 1, \mathrm{~s} 2]}$. That is, urea $(20 \mathrm{~g}$, AR, Sinopharm Chemical Reagent Co., Ltd) was put in a crucible with a cover under ambient pressure in air. After thermal treatment at $550{ }^{\circ} \mathrm{C}$ for 3 hours, the yellow colored $\mathrm{g}_{-} \mathrm{C}_{3} \mathrm{~N}_{4}$ was obtained. Then, the sample was washed with nitric acid $\left(0.1 \mathrm{~mol} \mathrm{~L}^{-1}\right)$ and distilled water (DI water).

Solution of Fe (III) $\left\{\mathrm{PO}_{4}\left[\mathrm{WO}\left(\mathrm{O}_{2}\right)_{2}\right]_{4}\right\}$ cluster: $\mathrm{FeCl}_{3} \cdot 6 \mathrm{H}_{2} \mathrm{O}(0.047 \mathrm{~g}$, AR, Sinopharm Chemical Reagent Co., Ltd) was dissolved in $100 \mathrm{~mL}$ ultrapure water (Millipore, 18.2 $\mathrm{M} \Omega \mathrm{cm})$ with $\mathrm{pH}$ at 1 under stirring. Then, $\mathrm{H}_{3} \mathrm{PW}_{12} \mathrm{O}_{40} \cdot \mathrm{xH}_{2} \mathrm{O}(0.22 \mathrm{~g}$, AR, Sinopharm Chemical Reagent Co., Ltd) was dissolved in above Fe (III) cations solution under strong stirring to obtain Fe (III) $\left\{\mathrm{PO}_{4}\left[\mathrm{WO}\left(\mathrm{O}_{2}\right)_{2}\right]_{4}\right\}$ cluster solution.

Supramolecualr hybrids photocatalyst $\left(\mathrm{FePW}-\mathrm{g}-\mathrm{C}_{3} \mathrm{~N}_{4}\right): 0.10 \mathrm{~g} \mathrm{~g}-\mathrm{C}_{3} \mathrm{~N}_{4}$ was dispersed into the solution of Fe (III) $\left\{\mathrm{PO}_{4}\left[\mathrm{WO}\left(\mathrm{O}_{2}\right)_{2}\right]_{4}\right\}$ cluster by bath sonicator for 0.5 hour. Following that, the dispersion was continuously stirred for another 12 hours. Finally, the dispersion was filtered and dried at $85{ }^{\circ} \mathrm{C}$ to obtain the sample.

\section{Characterization}

TEM and STEM images with EDX and elements mapping were obtained on Talos F200s (FEI, 200 kV). XRD patterns were identified by X'Pert Pro MPD (Cu Ka, $\lambda=$ $1.5406 \AA$ ). FTIR transmission spectra were performed on Nicolet 6700 IR spectrometer by using $\mathrm{KBr}$ pellets. XPS spectra were measured on an ESCALAB 250 $\mathrm{x}$-ray photoelectron spectrometer using $\mathrm{Al} \mathrm{K \alpha} \mathrm{x}$-ray as an excitation source. UV-Vis absorption spectra were measured on a TU-1910 (Beijing purkinje general instrument Co., Ltd). UV-Vis diffuse-reflectance spectra (UV-Vis DRS) were recorded on U4100 (SHIMADZU) with Integrating Sphere Attachment $\left(\mathrm{BaSO}_{4}\right.$ as a reflectance standard). Photoluminescence spectra (PL) were measured on FLS920 (Edinburgh Instruments). X-Ray fluorescence (XRF) was performed on XRF spectroscopy (Axios, Panalytical). Electron spin resonance spectroscopy (ESR) spectra were recorded on JES-FA200 (JEOL). Inductively Coupled Plasma Optical Emission Spectra (ICP-OES) were obtained on OPTIMA 3300DV (Perkin-Elmer). $\mathrm{N}_{2}$ adsorption-desorption isotherms 
were recorded on Quadrasorb SI Automated Surface area and Pore size analyzer (Quantachrome). Elemental analysis for $\mathrm{C}, \mathrm{N}, \mathrm{H}$ and $\mathrm{O}$ was measured on vario MACRO cube (Elementar).

\section{Photocatalytic test}

Adsorption and photocatalytic process under simulated solar light: Rhodamine B $(\mathrm{RhB})$ and Methyl Orange (MO) was used as a model organic pollutants (MOP) with the concentration of $10 \mathrm{mg} \mathrm{L}^{-1}(10 \mathrm{ppm})$. Supramolecular hybrids $\left(\mathrm{FePW}-\mathrm{g}-\mathrm{C}_{3} \mathrm{~N}_{4}\right)$ powder $(10 \mathrm{mg})$ as photocatalyst was dispersed in $100 \mathrm{~mL}$ MOP solution by sonication $10 \mathrm{~min}$ in a bath sonicator. Then, it was kept in the dark for 1 hour under stirring to reach saturation adsorption. After that, the photocatalytic process started under simulated solar light irradiation. The light source was a Xe lamp (PLS-SXE 300UV) with simulated solar light filter (AM1.5 with a total reflected filter). The cycling experiments were performed. After filtering the sedimentation of photocatalyst by a vacuum filter, the obtained one was re-dispersed in $100 \mathrm{~mL} \mathrm{RhB}$ or MO solution (initial concentration $10 \mathrm{mg} \mathrm{L}^{-1}$ ) by sonication for $10 \mathrm{~min}$. The adsorption and photocatalytic process were the same with the one mentioned above. Adsorption and photocatalytic process under Natural Sunlight: The photocatalytic process under Sun light was performed with location at 42 degree 15 minute North, 119 degree 15 minute East. Rhodamine B (RhB) and Methyl Orange (MO) was also used with the concentration of $10 \mathrm{mg} \mathrm{L}^{-1}(10 \mathrm{ppm})$. Supramolecular hybrids $\left(\mathrm{FePW}-\mathrm{g}-\mathrm{C}_{3} \mathrm{~N}_{4}\right)$ powder $(10 \mathrm{mg})$ as photocatalyst was dispersed in $100 \mathrm{~mL} \mathrm{RhB}$ or MO solution by sonication $10 \mathrm{~min}$ in a bath sonicator. Then, it was kept in the dark for 1 hour under stirring to reach saturation adsorption. After that, the photocatalytic process started under the sunlight. The cycling experiments were performed. After filtering the sedimentation of photocatalyst by a vacuum filter, the obtained one was re-dispersed in $100 \mathrm{~mL} \mathrm{RhB}$ or MO solution (initial concentration $10 \mathrm{mg} \mathrm{L}^{-1}$ ) by sonication for $10 \mathrm{~min}$. The adsorption and photocatalytic process were the same with the one mentioned above.

Time-dependent fluorescence signal for $\bullet \mathrm{OH}$ radical determination: $\bullet \mathrm{OH}$ radical reactions were performed as follows. $5 \mathrm{mg}$ of the photocatalyst was suspended in 80 
$\mathrm{mL}$ aqueous solution containing $0.01 \mathrm{M} \mathrm{NaOH}$ and $3 \mathrm{mM}$ terephthalic acid. Before exposure to Xe lamp light, the suspension was stirred in the dark for $30 \mathrm{~min} .5 \mathrm{~mL}$ of the solution was then removed every $5 \mathrm{~min}$ and centrifuged for fluorescence spectroscopy measurements. During the photoreactions, no oxygen was bubbled into the suspension. A fluorescence spectrophotometer was used to measure the fluorescence signal of the 2-hydroxy terephthalic acid generated. The excitation light wavelength used in recording fluorescence spectra was $320 \mathrm{~nm}$. 

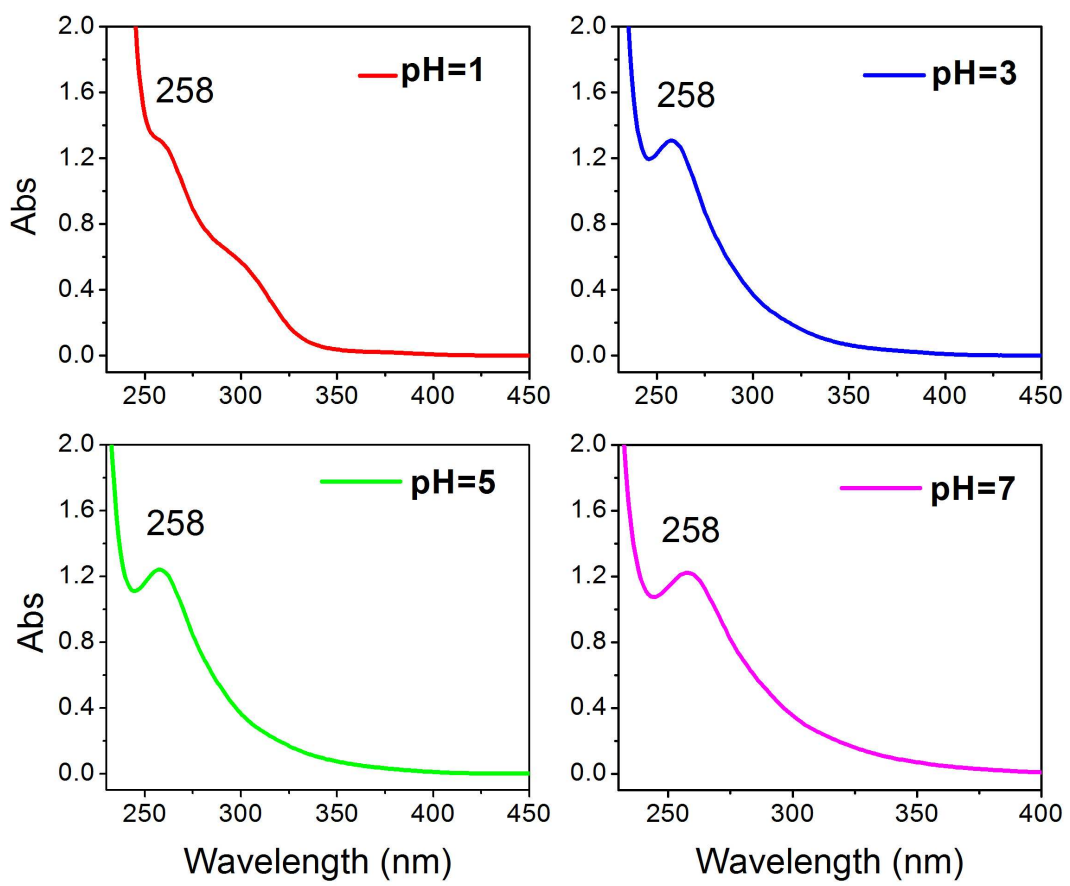

Figure S1 UV-Vis spectra of Fe (III) $\left\{\mathrm{PO}_{4}\left[\mathrm{WO}\left(\mathrm{O}_{2}\right)_{2}\right]_{4}\right\}(\mathrm{FePW})$ cluster for the hydrolysis-resistance capability at extended $\mathrm{pH}$ in water. 

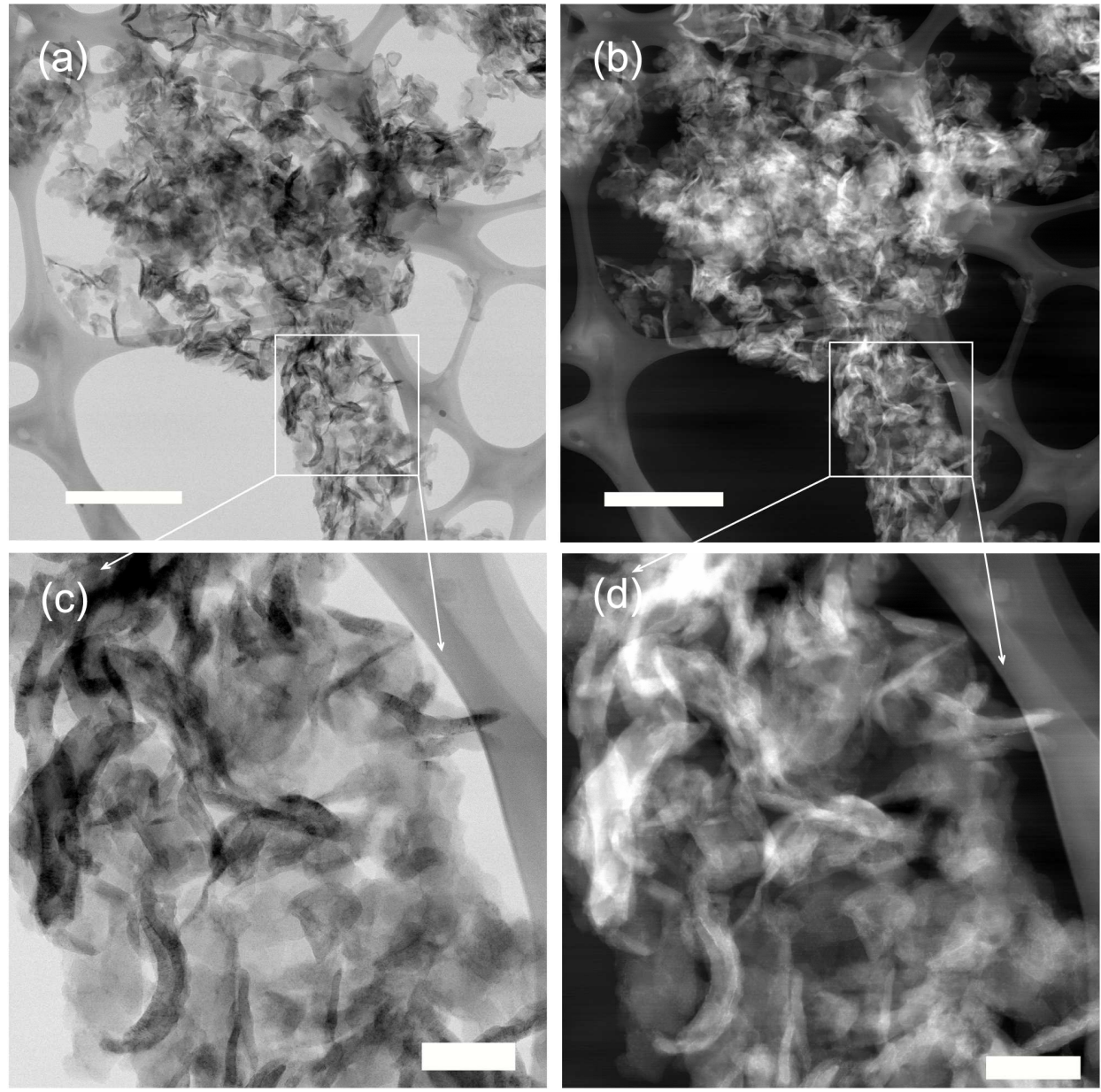

Figure S2 TEM and STEM images of FePW-g- $\mathrm{C}_{3} \mathrm{~N}_{4}$. (a) Bright field TEM image. Scale bar $500 \mathrm{~nm}$. (b) Corresponding high angle annular dark-field (HAADF)-STEM image. Scale bar $500 \mathrm{~nm}$. (c) Enlarged selected area TEM image. Scale bar $100 \mathrm{~nm}$. (d) Corresponding HAADF-STEM image. Scale bar $100 \mathrm{~nm}$. 

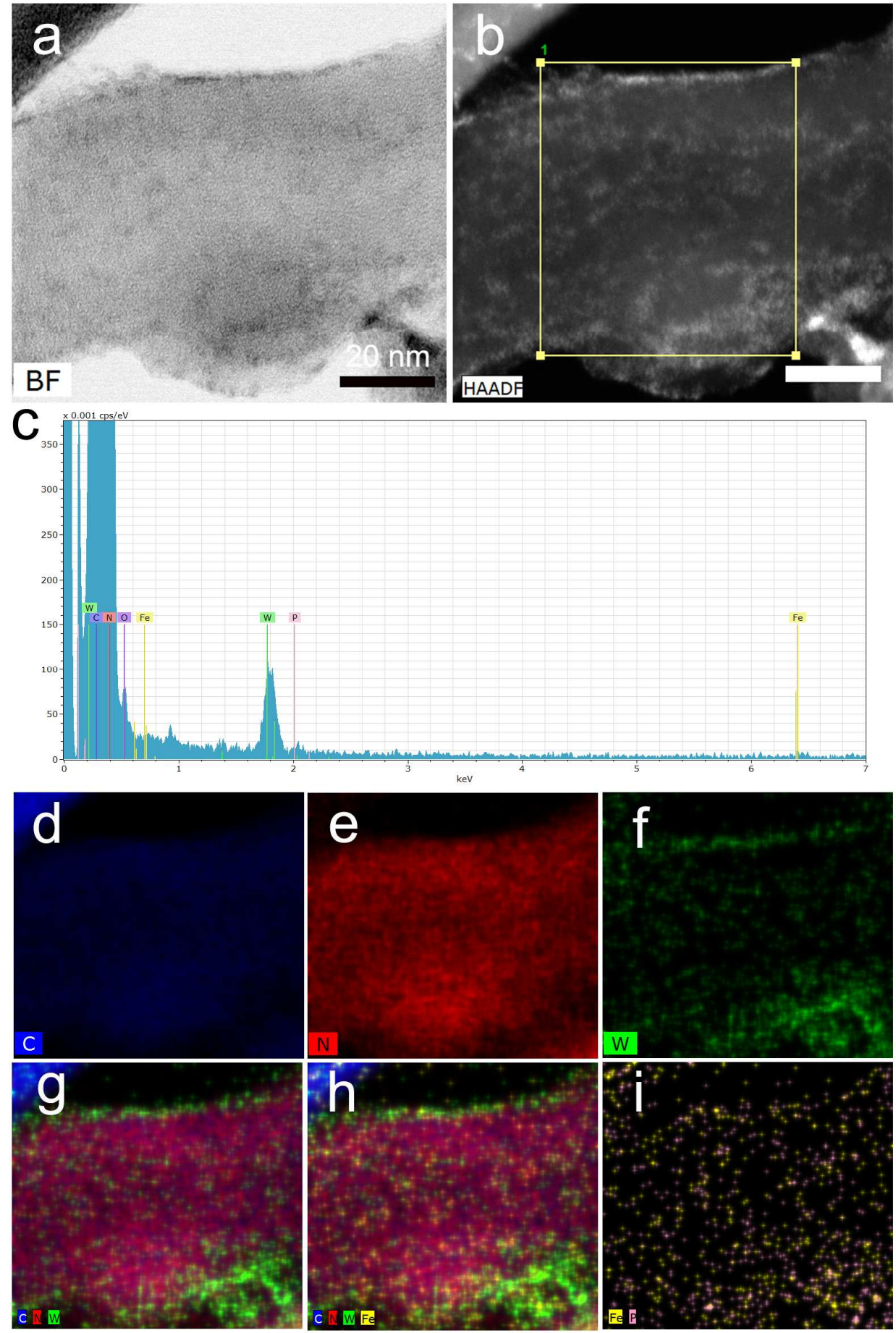

Figure S3 High resolution STEM and EDS elemental analysis of FePW-g- $\mathrm{C}_{3} \mathrm{~N}_{4}$ for observation of cluster localization. (a) bright-field (BF) TEM image. (b) HAADF-STEM image. (c) EDS elemental analysis in the area marked by yellow color square, and element mappings for C, N, Fe, P and W (d-i). Scale bar $20 \mathrm{~nm}$. 


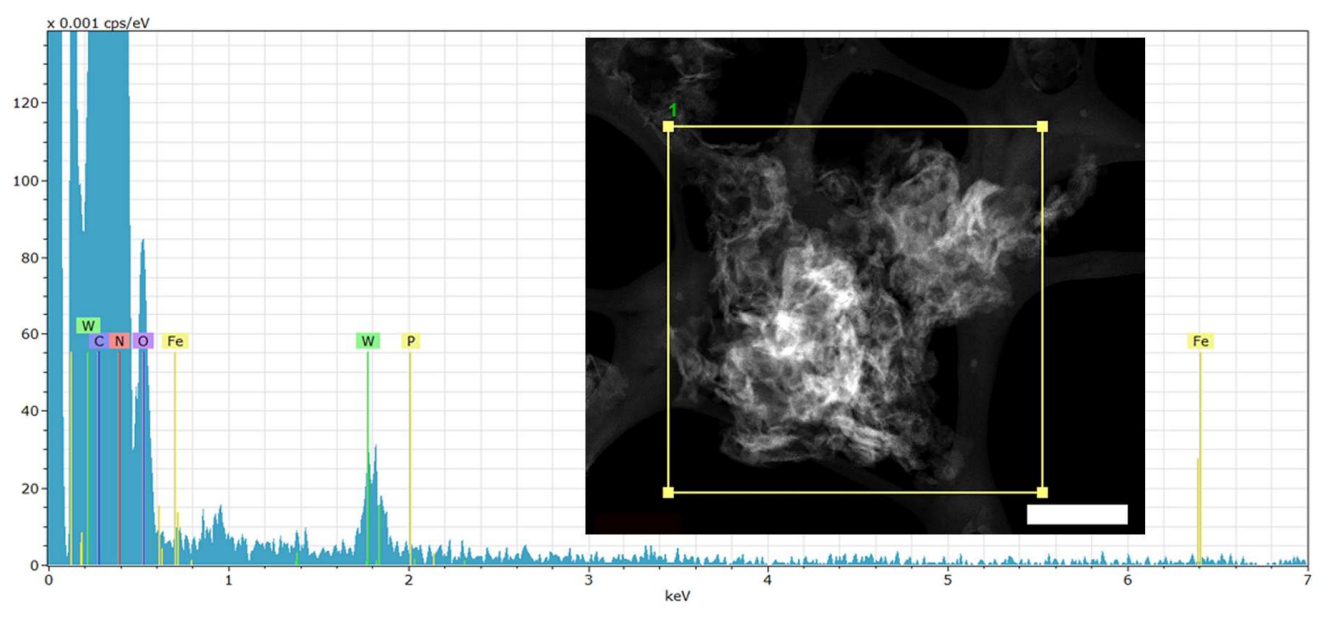

Figure S4 EDS elemental analysis in the area marked by yellow color square. Inset: STEM image. Scale bar $400 \mathrm{~nm}$. 

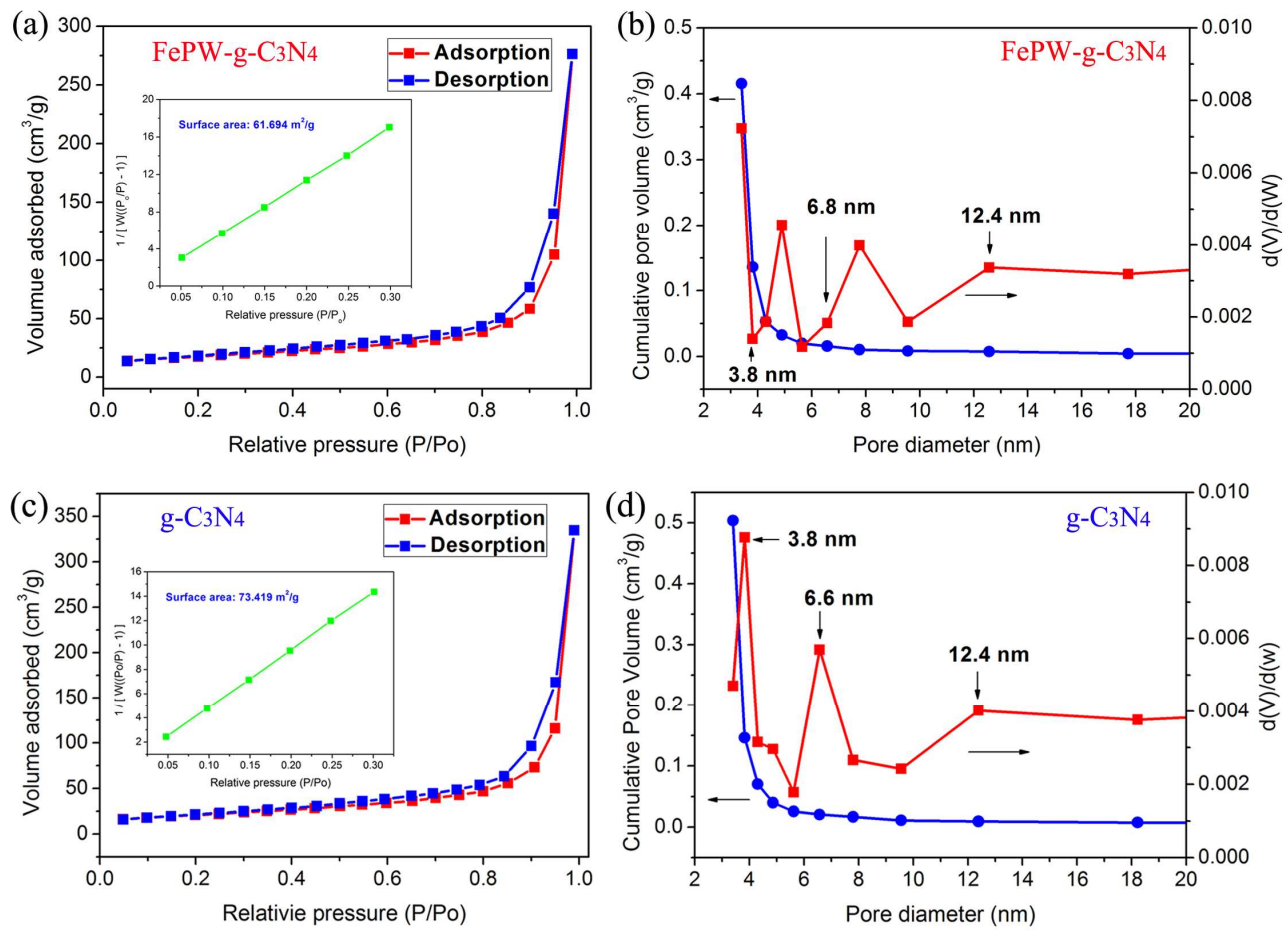

Figure S5 Specific surface area (SSA) and $\mathrm{BJH}$ pore size distributions for FePW-g- $\mathrm{C}_{3} \mathrm{~N}_{4}$ and g- $\mathrm{C}_{3} \mathrm{~N}_{4}$ control. (a) $\mathrm{N}_{2}$ adsorption/desorption isotherms. Inset: BET specific surface area (SSA). The SSA of FePW-g- $\mathrm{C}_{3} \mathrm{~N}_{4}$ is $61.694 \mathrm{~m}^{2} / \mathrm{g}$. (b) Pore size distribution and pore volume analyzed according to Barret-Joyner-Halenda (BJH) method for FePW-g- $\mathrm{C}_{3} \mathrm{~N}_{4}$. (c) $\mathrm{N}_{2}$ adsorption/desorption isotherms. Inset: BET specific surface area (SSA). The SSA of $\mathrm{g}-\mathrm{C}_{3} \mathrm{~N}_{4}$ is $73.419 \mathrm{~m}^{2} / \mathrm{g}$. (d) Pore size distribution and pore volume analyzed according to Barret-Joyner-Halenda $(\mathrm{BJH})$ method for $\mathrm{g}-\mathrm{C}_{3} \mathrm{~N}_{4}$. 
Table S1 XRF measurement for determination of Fe, P and W in FePW-g- $\mathrm{C}_{3} \mathrm{~N}_{4}$

\begin{tabular}{ccccccccc}
\hline Analyte & Calibration & Compound & Measured & Used & Concentration & Unit & Calculation & Status \\
\hline $\mathrm{Na}$ & Calibrated & $\mathrm{Na}$ & 0.192 & 0.154 & 0.024 & $\%$ & Calculate & $\mathrm{BgC}$ \\
\hline $\mathrm{Al}$ & Calibrated & $\mathrm{Al}$ & 0.319 & 0.287 & 0.014 & $\%$ & Calculate & $\mathrm{BgC}$ \\
\hline $\mathrm{Si}$ & Calibrated & $\mathrm{Si}$ & 0.787 & 0.681 & 0.027 & $\%$ & Calculate & $\mathrm{BgC}$ \\
\hline $\mathbf{P}$ & Calibrated & $\mathbf{P}$ & $\mathbf{4 . 9 9 1}$ & $\mathbf{4 . 8 5}$ & 0.062 & $\%$ & Calculate & $\mathrm{BgC}$ \\
\hline $\mathbf{C l}$ & Calibrated & $\mathbf{C l}$ & $\mathbf{1 . 4 0 2}$ & $\mathbf{0 . 7 7 1}$ & 0.02 & $\%$ & Calculate & $\mathrm{BgC}$ \\
\hline $\mathrm{Ca}$ & Calibrated & $\mathrm{Ca}$ & 0.661 & 0.556 & 0.012 & $\%$ & Calculate & $\mathrm{BgC}$ \\
\hline $\mathbf{F e}$ & Calibrated & $\mathbf{F e}$ & $\mathbf{3 . 3 2 6}$ & $\mathbf{3 . 0 2 1}$ & 0.048 & $\%$ & Calculate & $\mathrm{BgC}$ \\
\hline $\mathbf{W}$ & Calibrated & $\mathbf{W}$ & $\mathbf{3 6 . 7 0 7}$ & $\mathbf{3 5 . 9 4 9}$ & 0.332 & $\%$ & Calculate & $\mathrm{BgC}$ \\
\hline$<\mathrm{C}>$ & & $\mathrm{CO}$ & & & 99.461 & $\%$ & Balance \\
\hline
\end{tabular}

Table S2 ICP-AES for measuring the contents of Fe and P in FePW-g- $\mathrm{C}_{3} \mathrm{~N}_{4}$

\begin{tabular}{ccccccccc}
\hline Element & Mean Corr. & Mean & Std. Dev. & Calib & Mean & St. Dev. & Sample & RSD \\
& Intensity & Conc. & & Units & Conc. & & Units & \\
\hline Fe 238.204 & 5765.5 & $\mathbf{0 . 3 0 6}$ & 0.0012 & $\mathrm{mg} / \mathrm{L}$ & 0.306 & 0.0012 & $\mathrm{mg} / \mathrm{L}$ & $0.40 \%$ \\
P 213.617 & 221.8 & $\mathbf{0 . 1 2 4}$ & 0.0012 & $\mathrm{mg} / \mathrm{L}$ & 0.124 & 0.0012 & $\mathrm{mg} / \mathrm{L}$ & $4.25 \%$ \\
\hline
\end{tabular}

Fe wt $\%:(0.0153 \mathrm{mg} / 21.7 \mathrm{mg}) \times 100 \%=0.0705 \mathrm{wt} \%$;

P wt \%: $(0.0062 \mathrm{mg} / 21.7 \mathrm{mg}) \times 100 \%=0.0286 \mathrm{wt} \%$;

$\mathrm{n}(\mathrm{Fe}): \mathrm{n}(\mathrm{P})=0.274: 0.2=1.37$ 


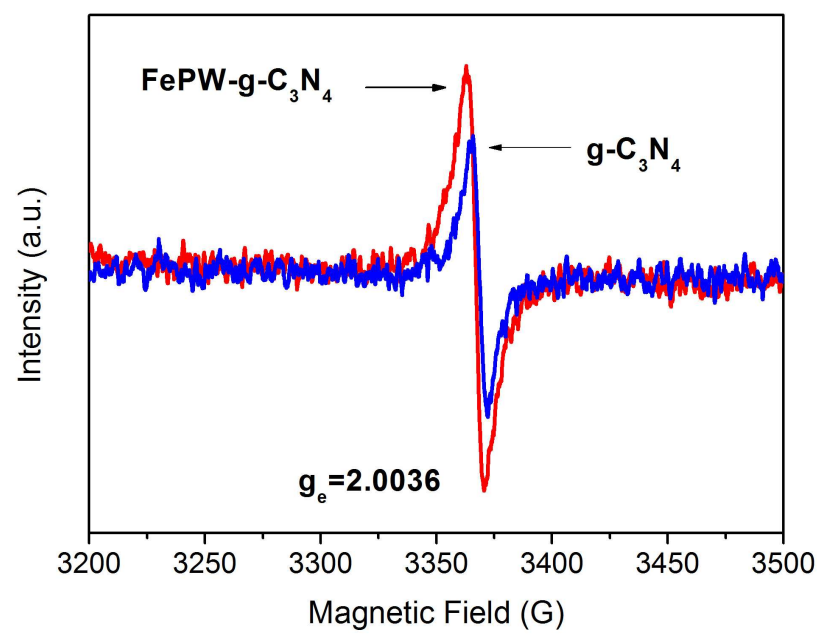

Figure S6 Electron Paramagnetic Resonance (EPR) spectra for FePW-g- $\mathrm{C}_{3} \mathrm{~N}_{4}$ and g- $\mathrm{C}_{3} \mathrm{~N}_{4}$. 

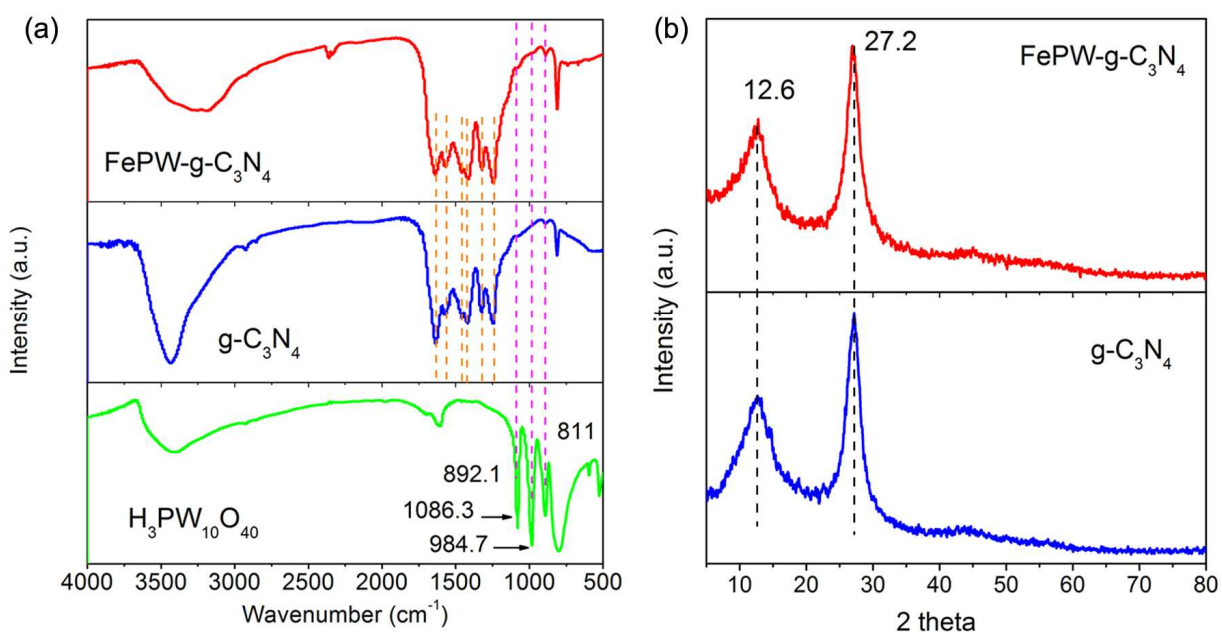

Figure S7 Supramolecular interactions and structural stability between Fe (III) $\left\{\mathrm{PO}_{4}\left[\mathrm{WO}\left(\mathrm{O}_{2}\right)_{2}\right]_{4}\right\}$ cluster and $\mathrm{g}-\mathrm{C}_{3} \mathrm{~N}_{4}$ in FePW-g-C $\mathrm{N}_{4}$ probed by FTIR (a) and XRD (b). 
Table S3 Elemental analysis (EA) measurement for $\mathrm{g}-\mathrm{C}_{3} \mathrm{~N}_{4}$

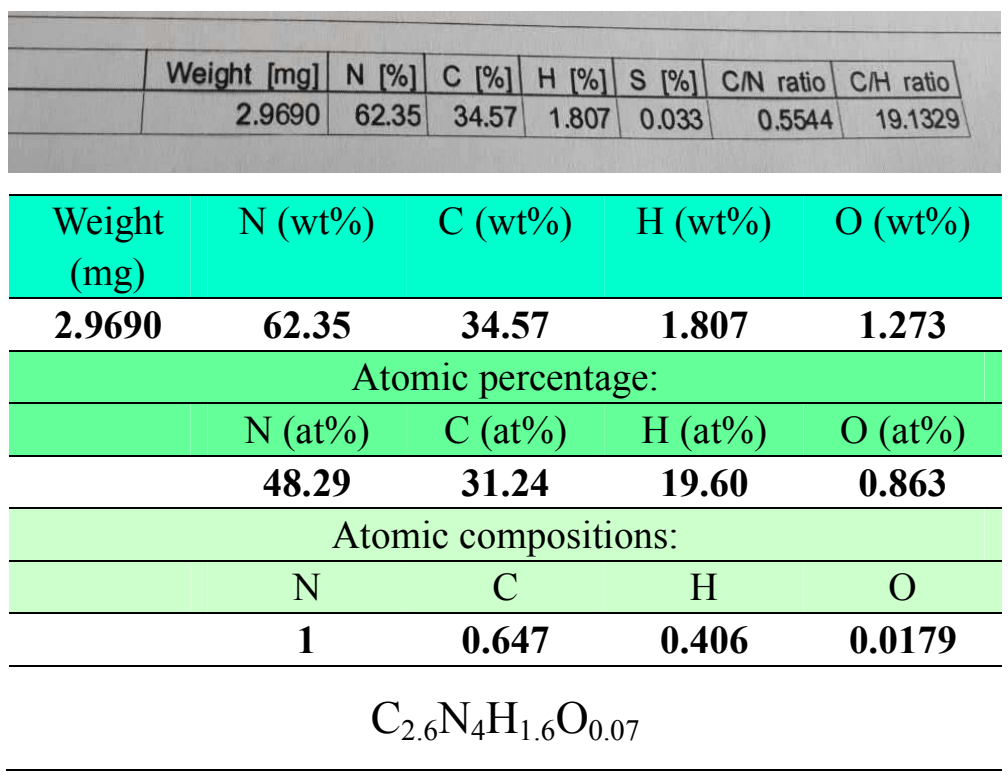

Table S4 Bulk and surface Compositions of $\mathrm{g}-\mathrm{C}_{3} \mathrm{~N}_{4}$ determined by EA and XPS

\begin{tabular}{cccccc}
\hline & $\mathrm{N}(\mathrm{at} \%)$ & $\mathrm{C}(\mathrm{at} \%)$ & $\mathrm{H}(\mathrm{at} \%)$ & $\mathrm{O}(\mathrm{at} \%)$ & $\begin{array}{c}\text { Atomic } \\
\text { compositions }\end{array}$ \\
\hline $\begin{array}{c}\text { Elemental } \\
\text { Analysis } \\
\text { (EA) }\end{array}$ & 48.29 & 31.24 & 19.60 & 0.863 & $\mathrm{C}_{2.6} \mathrm{~N}_{4} \mathrm{H}_{1.6} \mathrm{O}_{0.07}$ \\
\hline XPS & 38.22 & 55.45 & & 6.34 & $\mathrm{C}_{6} \mathrm{~N}_{4} \mathrm{O}_{0.68}$ \\
\hline
\end{tabular}




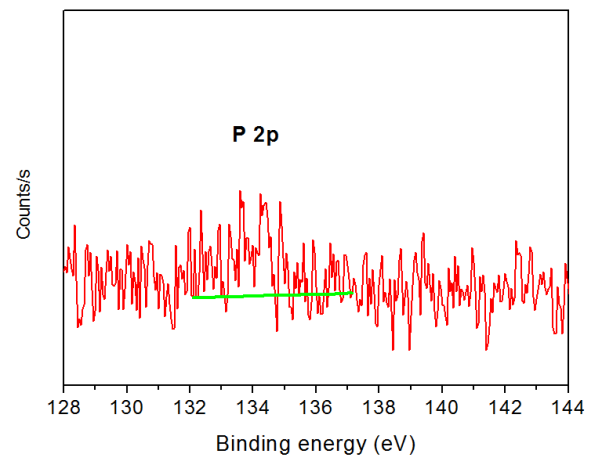

Figure S8 High resolution $\mathrm{P}_{2 \mathrm{p}}$ XPS spectra for FePW-g- $\mathrm{C}_{3} \mathrm{~N}_{4}$.
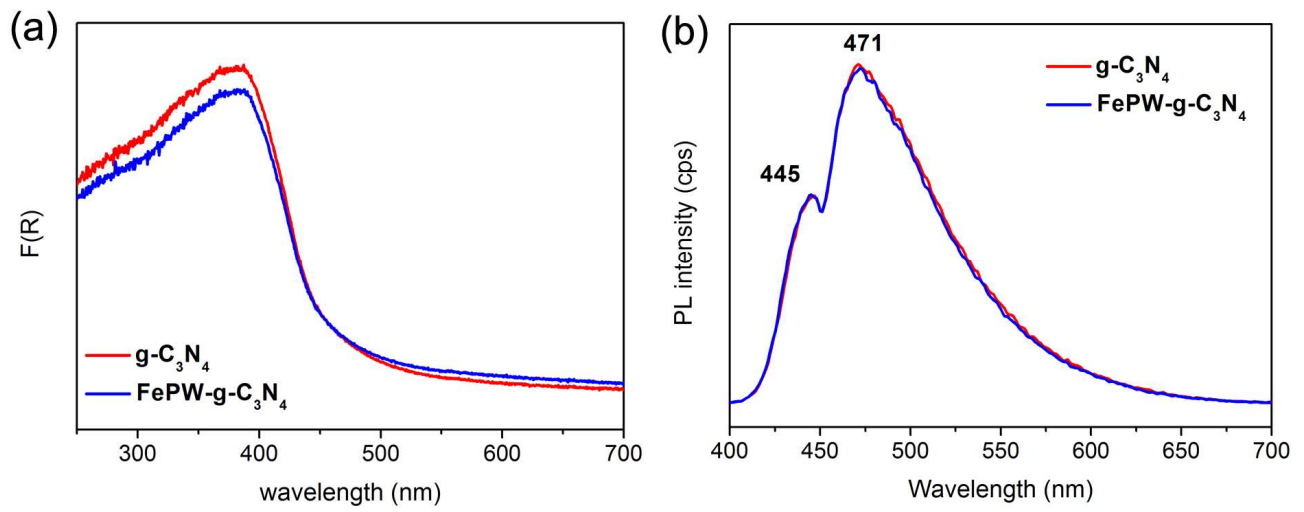

Figure S9 Optical properties of FePW-g- $\mathrm{C}_{3} \mathrm{~N}_{4}$. (a) UV-Visible diffuse-reflectance spectra (UV-Vis DRS). (b) Photoluminescence spectra (PL) with excitation wavelength at $388 \mathrm{~nm}$.

The optical properties of FePW-g- $C_{3} N_{4}$ was examined to determine the effects of the Fe (III) $\left\{\mathrm{PO}_{4}\left[\mathrm{WO}\left(\mathrm{O}_{2}\right)_{2}\right]_{4}\right\}$ cluster. The UV-Vis DRS spectra and PL spectra shows that the clusters have scarcely influences on the optical properties of $g-C_{3} N_{4}$. 


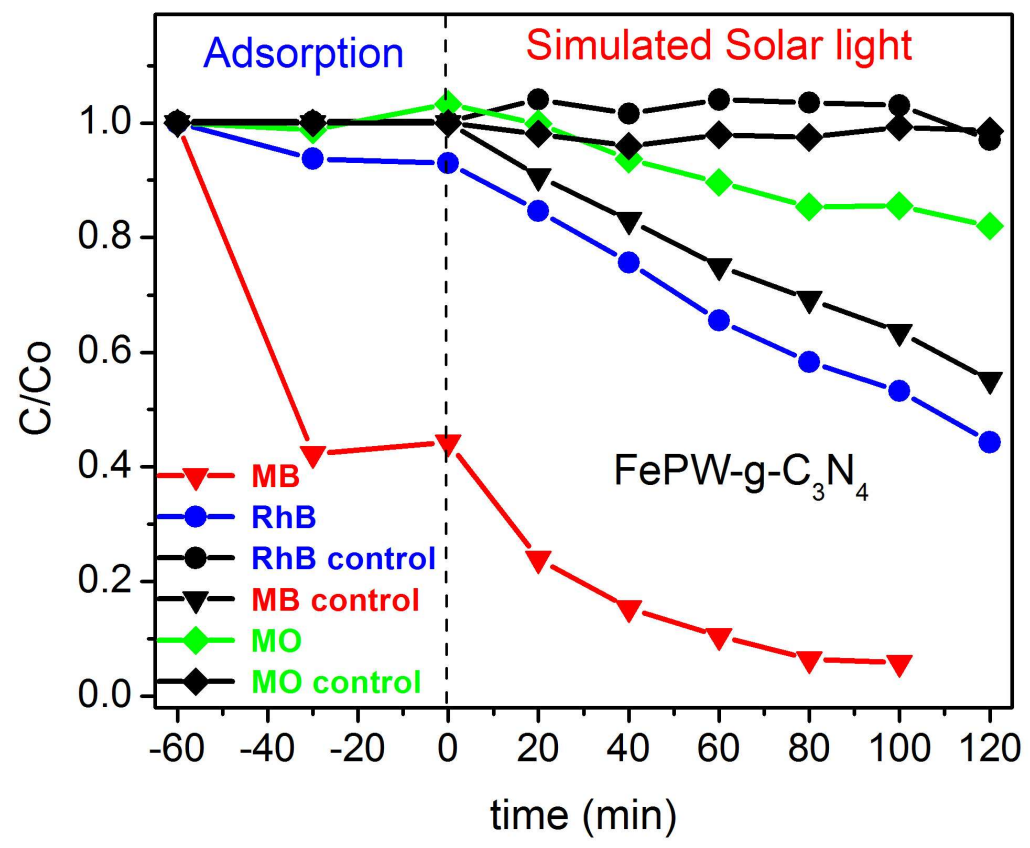

Figure S10 Adsorption guided photocatalytic selectivity of FePW-g- $\mathrm{C}_{3} \mathrm{~N}_{4}$ for methylene blue (MB), Rhodamine B (RhB) and Methyl Orange (MO) in water without $\mathrm{H}_{2} \mathrm{O}_{2}$ mediation under simulated solar light irradiation. 

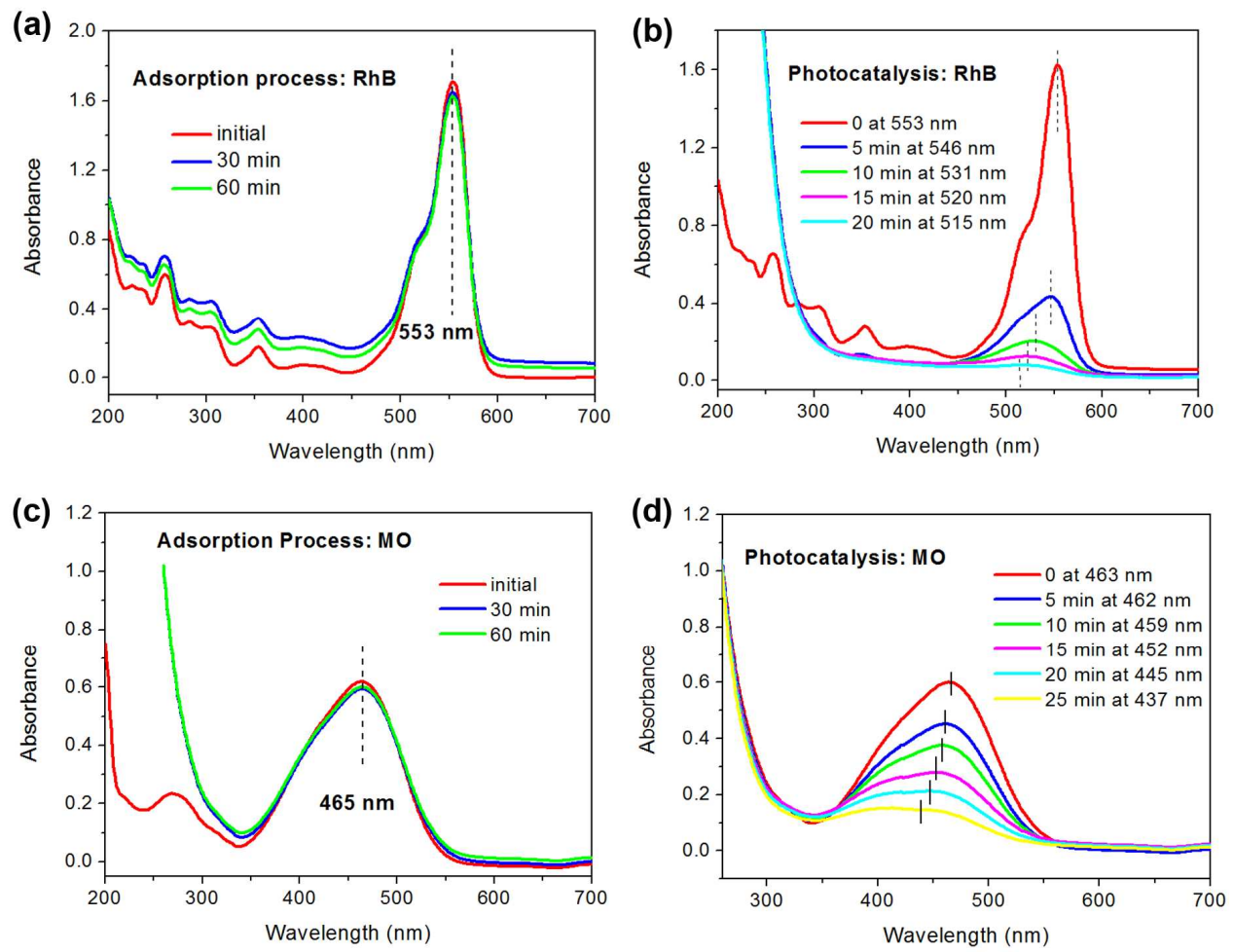

Figure S11 UV-Vis spectra for RhB and MO during adsorption and photocatalytic process. (a) Non-shifted absorption peaks of $\mathrm{RhB}$ in solution during adsorption process. (b) Blue-shifted absorption peaks of $\mathrm{RhB}$ in solution during photocatalytic process. (c) Non-shifted absorption peaks of MO in solution during adsorption process. (d) Blue-shifted absorption peaks of MO in solution during photocatalytic process. 


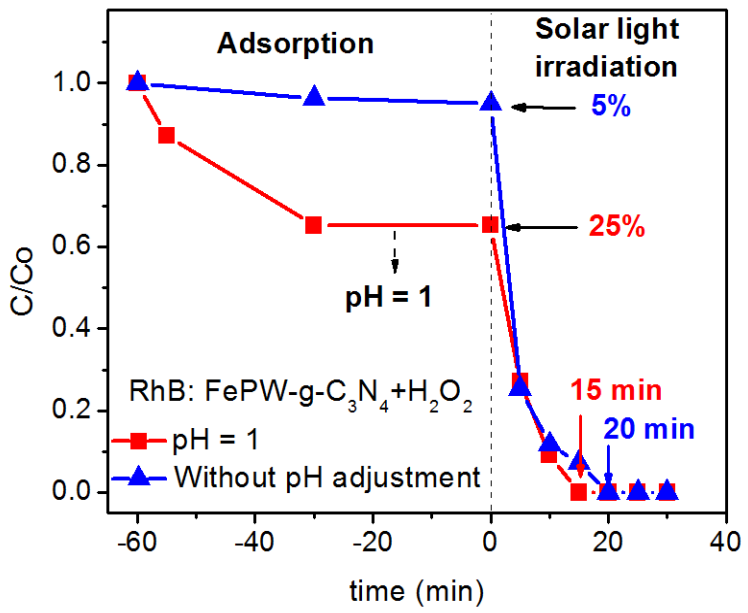

Figure S12 Influences of $\mathrm{pH}$ on adsorption capacity and photocatalytic activity of FePW-g- $\mathrm{C}_{3} \mathrm{~N}_{4}$ for Rhodamine B (RhB). 


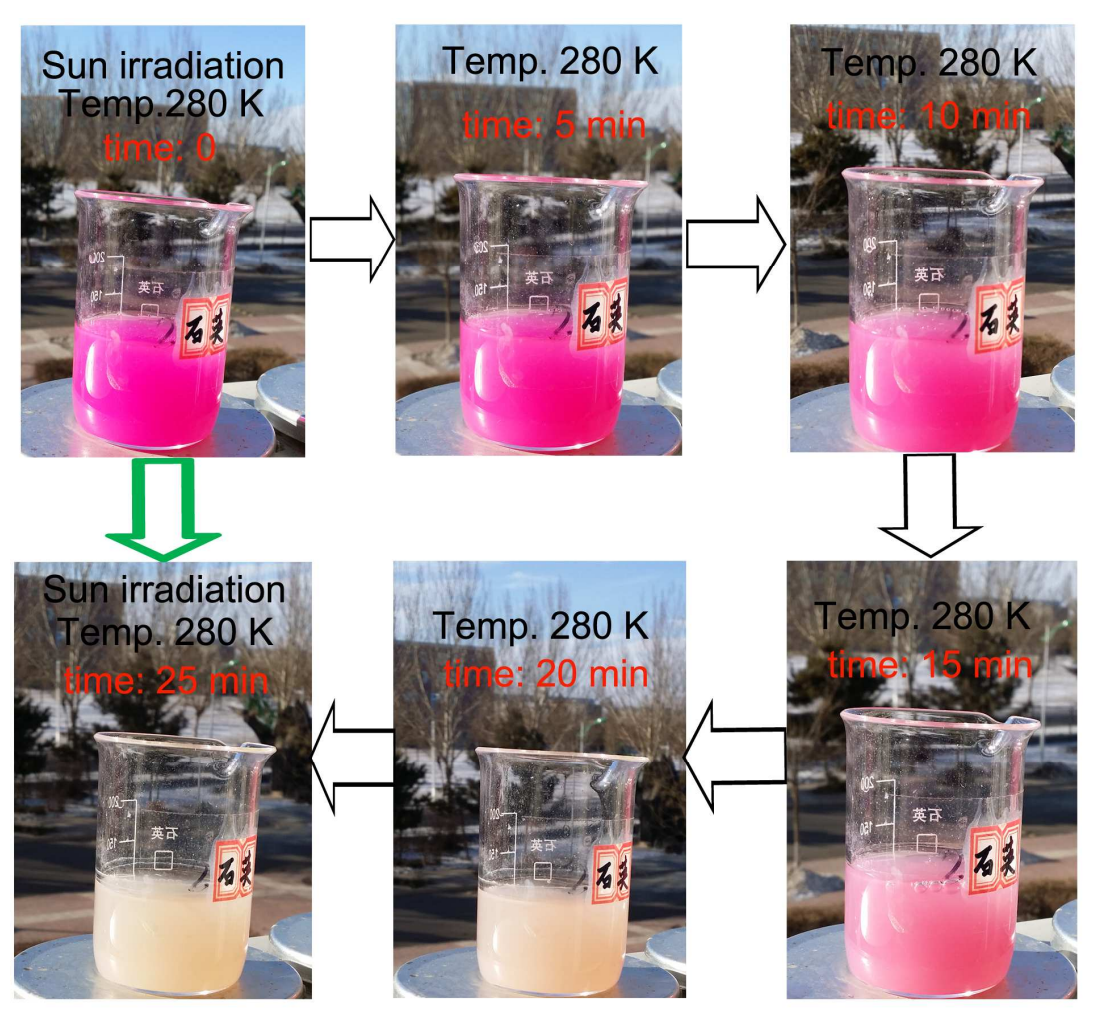

Figure S13 Photos for photocatalytic process of FePW-g- $\mathrm{C}_{3} \mathrm{~N}_{4}$ with $\mathrm{H}_{2} \mathrm{O}_{2}$ for degrading RhB (100 mL, $\left.10 \mathrm{mg} \mathrm{L}^{-1}\right)$ under the natural sunlight in winter at $\mathbf{2 8 0} \mathbf{~ K}$, taken at different irradiation time (location at 42 degree 15 minute North, 119 degree 15 minute East, and time from 12:00 to 14:00), where the FePW-g-C $\mathrm{N}_{3}$ is $0.1 \mathrm{~g} \mathrm{~L}^{-1}$ with $\mathrm{H}_{2} \mathrm{O}_{2}$ of $50 \mathrm{mmol} \mathrm{L}^{-1}$. 

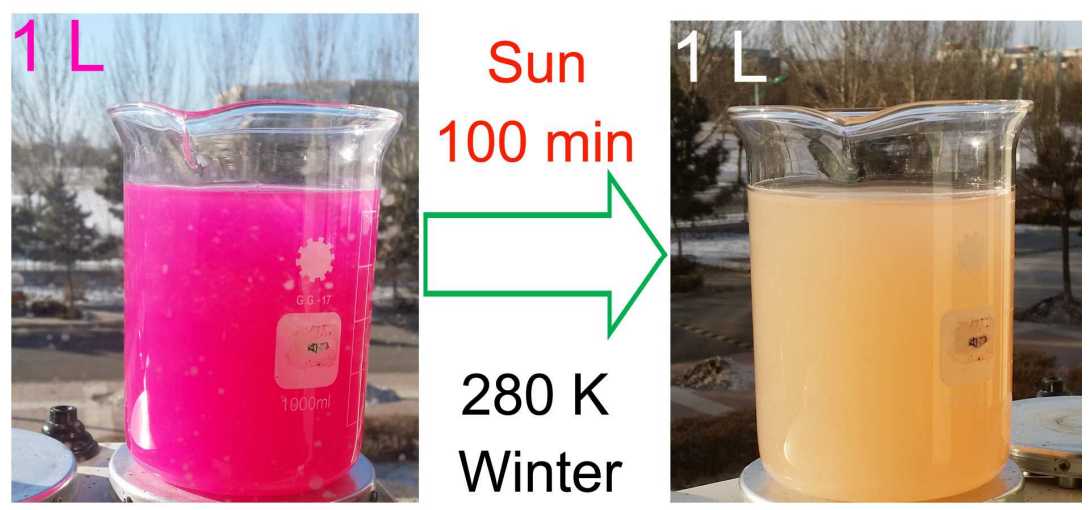

Figure S14 Scale-up application of FePW-g- $\mathrm{C}_{3} \mathrm{~N}_{4}$ for photocatalytic degradation of $\mathrm{RhB}\left(10 \mathrm{mg} \mathrm{L}^{-1}\right)$ at $1 \mathrm{~L}$ under the natural sunlight irradiation (location at 42 degree 15 minute North, 119 degree 15 minute East, and time from 12:00 to 14:00), where the FePW-g- $\mathrm{C}_{3} \mathrm{~N}_{4}$ is $0.05 \mathrm{~g} \mathrm{~L}^{-1}$ with $\mathrm{H}_{2} \mathrm{O}_{2}$ of $25 \mathrm{mmol} \mathrm{L}^{-1}$. 


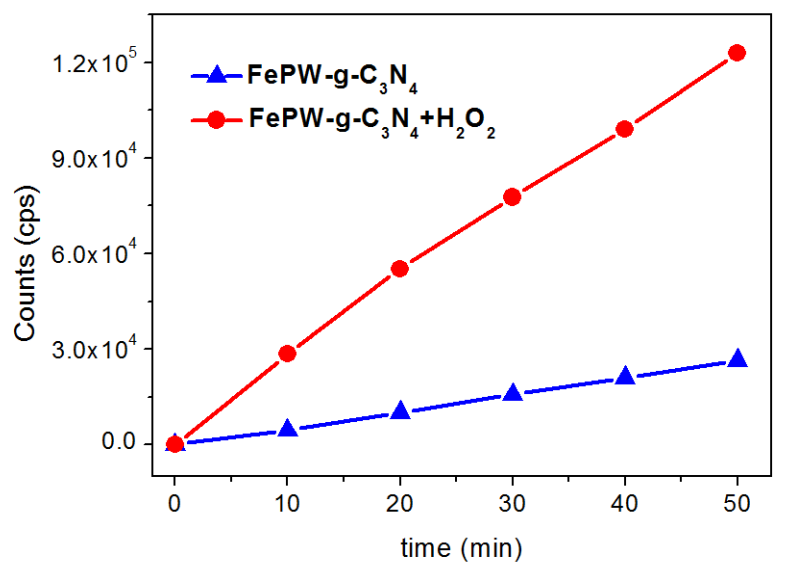

Figure S15 Time-dependent fluorescence signal intensity at $426 \mathrm{~nm}$ of 2-hydroxyterephthalic acid generated by reacting teraphthalic acid with $\bullet \mathrm{OH}$ radicals in the aqueous suspension of FePW-g- $\mathrm{C}_{3} \mathrm{~N}_{4}$ mediated with $\mathrm{H}_{2} \mathrm{O}_{2}$ under the irradiation of Xe lamp. 

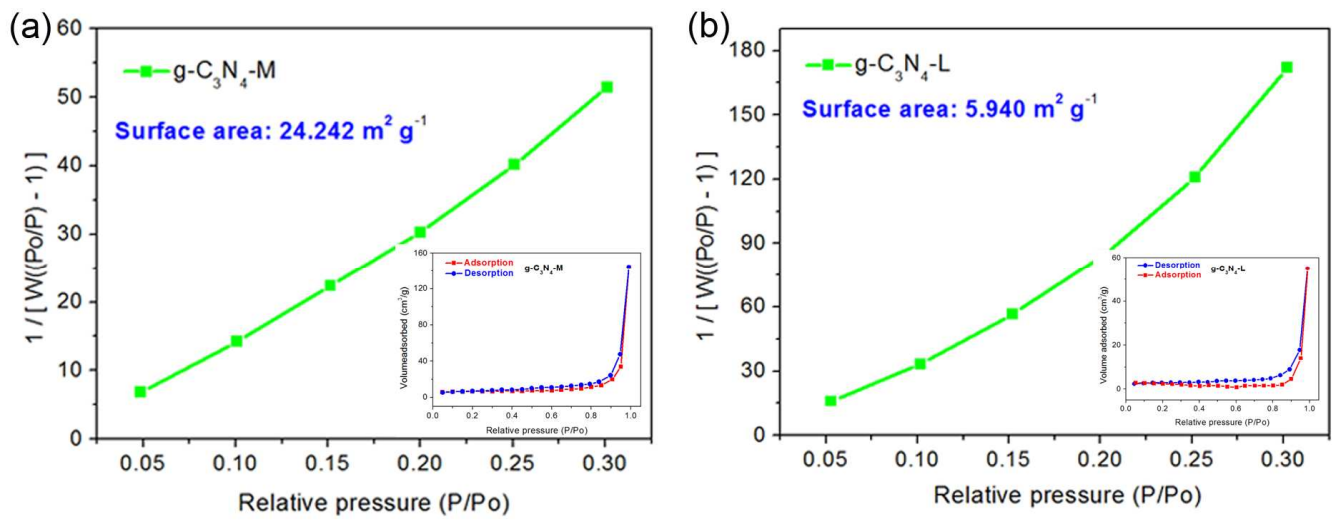

Figure S16 Specific surface area (SSA) of $g-\mathrm{C}_{3} \mathrm{~N}_{4}$. (a) $\mathrm{g}-\mathrm{C}_{3} \mathrm{~N}_{4}-\mathrm{M}$ with SSA of 24.242 $\mathrm{m}^{2} \mathrm{~g}^{-1}$ and (b) $\mathrm{g}-\mathrm{C}_{3} \mathrm{~N}_{4}-\mathrm{L}$ with SSA of $5.940 \mathrm{~m}^{2} \mathrm{~g}^{-1}$.

Table S5 Surface compositions determined by XPS for $\mathrm{g}_{-} \mathrm{C}_{3} \mathrm{~N}_{4}-\mathrm{L}$ and $\mathrm{g}-\mathrm{C}_{3} \mathrm{~N}_{4}-\mathrm{M}$

\begin{tabular}{lcccc}
\hline & $\mathrm{C}($ at $\%)$ & $\mathrm{N}($ at $\%)$ & $\mathrm{O}($ at\%) & $\begin{array}{c}\text { Atomic } \\
\text { compositions }\end{array}$ \\
\hline $\mathbf{g}-\mathbf{C}_{\mathbf{3}} \mathbf{N}_{\mathbf{4}}-\mathbf{L}$ & 54.36 & 40.51 & 5.12 & $\mathrm{C}_{1.3} \mathrm{NO}_{0.13}$ \\
\hline $\mathbf{g}-\mathbf{C}_{\mathbf{3}} \mathbf{N}_{\mathbf{4}}-\mathbf{M}$ & 57.66 & 34.57 & 7.77 & $\mathrm{C}_{1.6} \mathrm{NO}_{0.22}$ \\
\hline $\mathbf{g}-\mathbf{C}_{\mathbf{3}} \mathbf{N}_{\mathbf{4}}-\mathbf{H}$ & 55.45 & 38.22 & 6.34 & $\mathrm{C}_{1.5} \mathrm{NO}_{0.17}$ \\
\hline
\end{tabular}



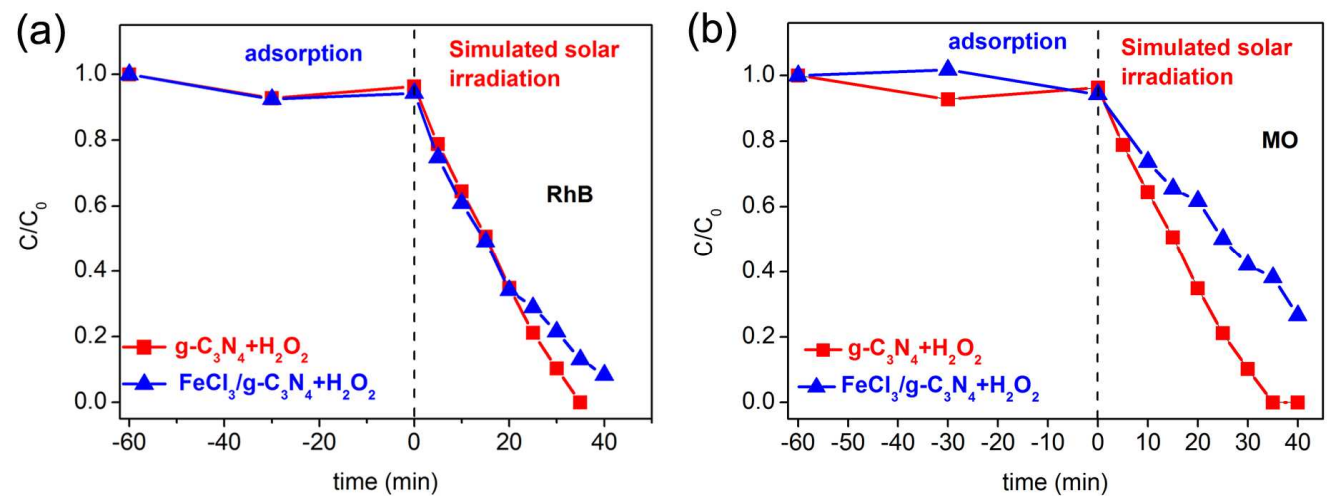

Figure S17 Adsorption and photocatalytic degradation of $\mathrm{RhB}$ (a) and $\mathrm{MO}$ (b) by $\mathrm{FeCl}_{3} / \mathrm{g}-\mathrm{C}_{3} \mathrm{~N}_{4}$ mediated by $\mathrm{H}_{2} \mathrm{O}_{2}$ under simulated solar light irradiation for mechanism investigation of the origin of high photocatalytic activity of FePW-g- $\mathrm{C}_{3} \mathrm{~N}_{4}$.

$\mathrm{FeCl}_{3} / \mathrm{g}-\mathrm{C}_{3} \mathrm{~N}_{4}$ was prepared by the same method as the FePW-g-C $\mathrm{C}_{3} \mathrm{~N}_{4}$ That is,

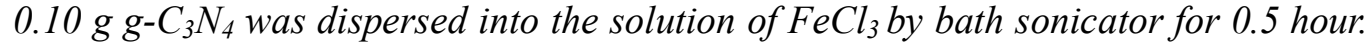
Following that, the dispersion was continuously stirred for another 12 hours. Finally, the dispersion was filtered and dried at $85{ }^{\circ} \mathrm{C}$ to obtain the sample.

Calculation equation for $\mathrm{FePW}_{4}$ as normalized activity

Relative activity (Ra) of $\mathrm{FePW}_{4}$ at $\mathrm{FePW}-\mathrm{g}-\mathrm{C}_{3} \mathrm{~N}_{4}$ to $\mathrm{g}-\mathrm{C}_{3} \mathrm{~N}_{4}$ :

$$
\mathrm{Ra}\left(\mathrm{FePW}_{4}\right)=\frac{\mathrm{A}\left(\mathrm{FePW}-\mathrm{g}-\mathrm{C}_{3} \mathrm{~N}_{4}\right)}{\mathrm{A}\left(\mathrm{g}-\mathrm{C}_{3} \mathrm{~N}_{4}\right)} \quad \text { (A: activity) equation } 1
$$

Normalized activity (Na):

$$
\begin{gathered}
\mathrm{Na}\left(\mathrm{FeCl}_{3}\right)=\frac{\mathrm{Ra}\left(\mathrm{FeCl}_{3}\right)}{\mathrm{Ra}\left(\mathrm{FePW}_{4}\right)}\left(\mathrm{Ra}\left(\mathrm{FeCl}_{3}\right) \text { was calculated by equation 1) equation } 2\right. \\
\mathrm{Na}(\mathrm{MgPW})=\frac{\mathrm{Ra}(\mathrm{MgPW})}{\mathrm{Ra}\left(\mathrm{FePW}_{4}\right)}(\mathrm{Ra}(\mathrm{MgPW}) \text { was calculated by equation 1) equation } 3
\end{gathered}
$$


(a)

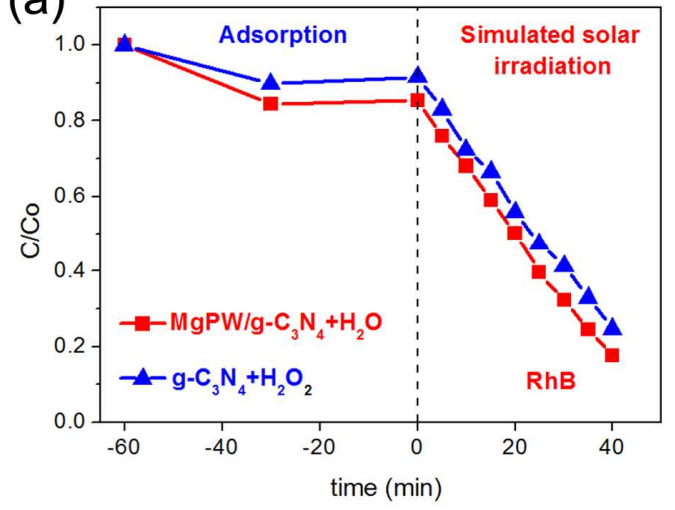

(b)

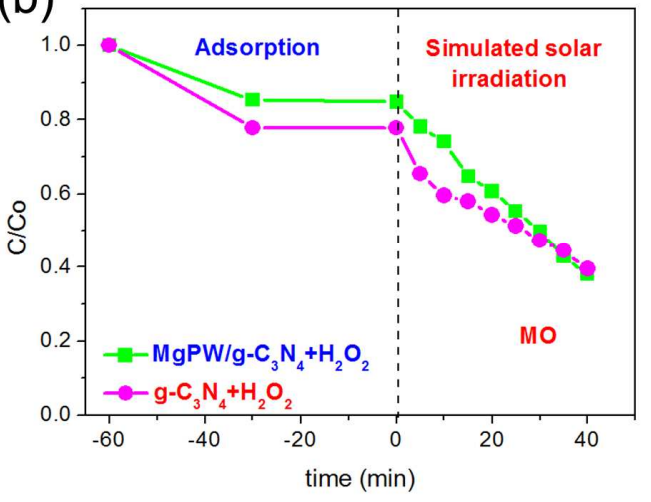

Figure S18 Adsorption and photocatalytic degradation of RhB (a) and $\mathrm{MO}$ (b) by $\mathrm{MgPW} / \mathrm{g}-\mathrm{C}_{3} \mathrm{~N}_{4}$ mediated by $\mathrm{H}_{2} \mathrm{O}_{2}$ under simulated solar light irradiation for mechanism investigation of the origin of high photocatalytic activity of FePW-g- $\mathrm{C}_{3} \mathrm{~N}_{4}$.

$\mathrm{MgPW} / \mathrm{g}-\mathrm{C}_{3} \mathrm{~N}_{4}$ was prepared by the same method as the FePW-g-C $\mathrm{C}_{3}$. That is,

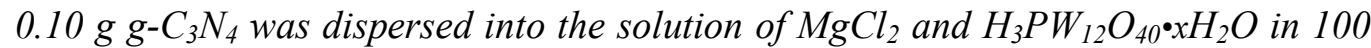
$m L$ ultrapure water (Millipore, $18.2 \mathrm{M} \Omega \mathrm{cm}$ ) with $\mathrm{pH}$ at 1 by bath sonicator for 0.5 hour. Following that, the dispersion was continuously stirred for another 12 hours. Finally, the dispersion was filtered and dried at $85^{\circ} \mathrm{C}$ to obtain the sample. 


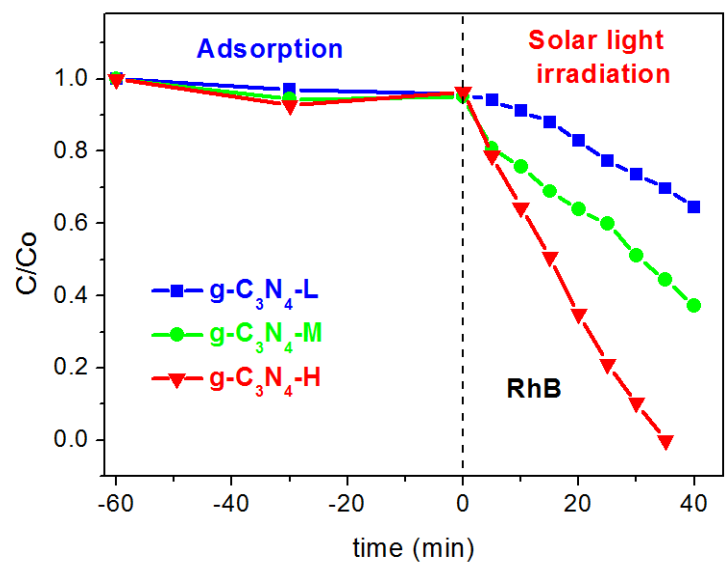

Figure S19 Effects of specific surface area (SSA) on photocatalytic activity of $g-\mathrm{C}_{3} \mathrm{~N}_{4}$ mediated by $\mathrm{H}_{2} \mathrm{O}_{2}$ under simulated solar light irradiation. $\mathrm{g}-\mathrm{C}_{3} \mathrm{~N}_{4}-\mathrm{L}$ with SSA of 5.94 $\mathrm{m}^{2} \mathrm{~g}^{-1}, \mathrm{~g}-\mathrm{C}_{3} \mathrm{~N}_{4}-\mathrm{M}$ with SSA of $20.24 \mathrm{~m}^{2} \mathrm{~g}^{-1}$ and $\mathrm{g}-\mathrm{C}_{3} \mathrm{~N}_{4}-\mathrm{H}$ with SSA of $73.42 \mathrm{~m}^{2} \mathrm{~g}^{-1}$. 

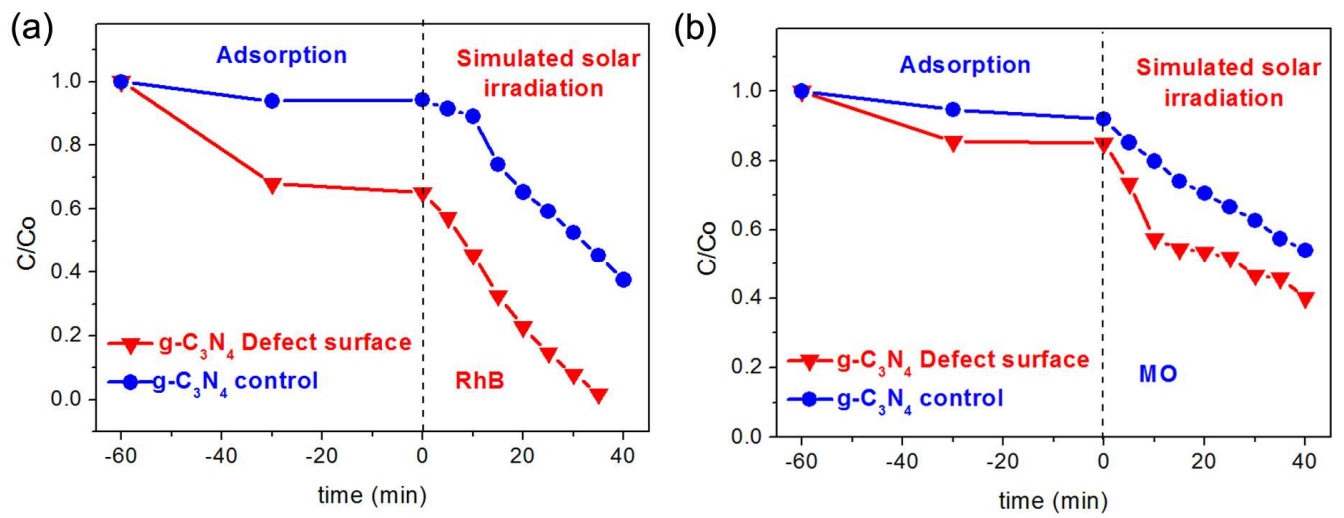

Figure S20 Effects of surface defects on photocatalytic activity of $\mathrm{g}-\mathrm{C}_{3} \mathrm{~N}_{4}$ for degradation of $\mathrm{RhB}$ (a) and $\mathrm{MO}$ (b), mediated by $\mathrm{H}_{2} \mathrm{O}_{2}$ under simulated solar light irradiation.

The g- $\mathrm{C}_{3} \mathrm{~N}_{4}$ control was prepared according to our previous method ${ }^{[s 3]}$. That is, $50 g$ urea (AR, Sinopharm Chemical Reagent Co.,Ltd) was placed in a covered corundum crucible and heated to550 ${ }^{\circ} \mathrm{C}$ at temperature increase rate of $10^{\circ} \mathrm{C} / \mathrm{min}$ and preserved for 3 hours in air atmosphere and naturally cooled to room temperature in a tube furnace. Then, the sample was washed with nitric acid $\left(0.1 \mathrm{~mol} \mathrm{~L}^{-1}\right)$ and distilled water (DI water) followed by filtering and drying at $80^{\circ} \mathrm{C}$. 

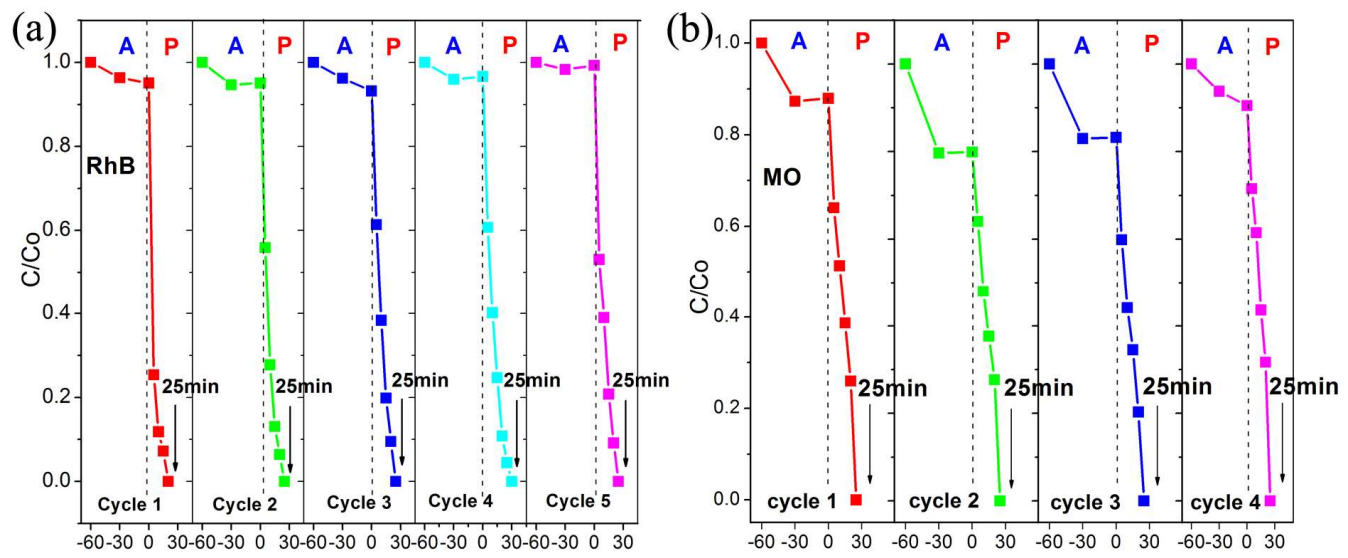

Figure S21 Cycling stability of FePW-g- $\mathrm{C}_{3} \mathrm{~N}_{4}$ for $\mathrm{RhB}\left(100 \mathrm{~mL}, 10 \mathrm{mg} \mathrm{L}^{-1}\right)$ (a) under simulated solar light irradiation and for MO $\left(100 \mathrm{~mL}, 10 \mathrm{mg} \mathrm{L}^{-1}\right)(\mathrm{b})$ under the natural sunlight irradiation (location at 42 degree 15 minute North, 119 degree 15 minute East, and with time from 12:00 to 14:00), where the FePW-g-C $\mathrm{C}_{3} \mathrm{~N}_{4}$ is $0.1 \mathrm{~g} \mathrm{~L}^{-1}$ with $\mathrm{H}_{2} \mathrm{O}_{2}$ of $50 \mathrm{mmol} \mathrm{L}^{-1}$.

[S1] J. H. Liu, T. K. Zhang, Z. C. Wang, G. Dawson, W. Chen, J. Mater. Chem. 2011, $21,14398-14401$.

[S2] J. H. Liu, Y. W. Zhang, L. L. Lu, G. Wu, W. Chen, Chem. Comm. 2012, 48, 8826-8828.

[S3] Z. Zhang, Y.J. Zhang, L. H. Lu, Y. J. Si, S. Zhang, Y. Chen, K. Dai, P. Duan, L. M. Duan, J. H. Liu, Appl. Surf. Sci., 2016, DOI:10.1016/j.apsusc.2016.05.174. 